ORIGINAL PROF-2333

\title{
DOWN'S SYNDROME;
}

\section{Congenital heart disease in children, an experience in Faisalabad Pakistan}

Dr. Shakil Ahmad, Dr. Imran Sarwar, Dr. Nisar Khan Sajid

ABSTRACT... Objective: To evaluate the various types of congenital heart defects and to determine their frequency in children with Down's syndrome. Study Design: Descriptive study. Place and duration of study: Department of Pediatrics, Independent University Hospital Faisal Abad Pakistan, from January 2010 to December 2012. Methodology: 93 children between the ages of day 1 to 12 years, diagnosed clinically as Down's syndrome based on its characteristic phenotypic appearance, were included in the study. A detailed history, physical examination and evaluation of cardiovascular status (including Chest x-ray, Electrocardiogram and Echocardiography) were performed in each Down's syndrome case. Variables of interest included age, sex, maternal age at birth and type and frequency of congenital heart disease. Results: Congenital heart disease was present in 48 (51.62\%) children out of 93 children with Down's syndrome. Congenital cardiac defects in order of predominant type and their frequency included Ventricular septal defect (29, 60.4\%), Atrioventricular septal defect (14, 29.1\%), Atrial septal defect (2, 4.1\%), Patent ductus arteriosis (2, 4.1\%) and Tetralogy of Fallots (1, $2 \%) .68(73.2 \%)$ Down's syndrome children $(n=93)$ presented during their first year of life with mean age of $7 \pm 4$ months. Male predominance was observed in both with and without congenital heart disease Down's syndrome children (male: female 1.7:1 and 2.5:1 respectively). Mean maternal age at birth was $27 \pm 2$ years. Conclusions: Congenital heart disease (CHD) is frequently associated with Down's syndrome (DS). Ventricular septal defects and atrioventricular septal defects are the most common forms of CHDs in DS children of our region. Their earlier presentation (in infancy) and significant contribution to the morbidity and mortality of DS children warrants early diagnosis of DS and mandatory screening of all DS children for associated CHDs.

Key words: Down's syndrome, Children, Congenital heart disease

Article Citation

Ahmad S, Sarwar I, Sajid NK. Down's syndrome; congenital heart disease in children, an experience in Faisal Abad Pakistan. Professional Med J 2013;20(6): 898-903.

\section{INTRODUCTION}

Down's syndrome (DS) or Trisomy 21, the most frequent and best known chromosomal disorder among children is characterized by mental retardation, hypotonia, dysmorphic facial features and other distinctive phenotypic traits ${ }^{1-3}$. Its frequency is about 1 case in 800 to 1,000 live births ${ }^{4}$. In $95 \%$ of cases, Trisomy 21 occurs due to maternal meiosis I nondisjunction whereas $4 \%$ are due to parental/de novo translocation and $1 \%$ due to mosaicism ${ }^{5,6}$. The risk of having a child with Down syndrome increases with increasing maternal age ${ }^{7}$.

Besides mental retardation and hypotonia, which are present in virtually all DS children, children with DS are at an increased risk for congenital heart defects, gastrointestinal defects, deafness, leukemia, hypothyroidism and Alzheimer's disease. The frequency of these phenotypic traits ranges from about $1 \%$ for leukemia, $12 \%$ for various gastrointestinal and
10 to $40 \%$ or more for congenital heart disease $(\mathrm{CHD})^{8-}$ 14

DS is frequently associated with congenital heart defects (CHDs). The frequency of CHDs in DS varies greatly in the literature, from 20 to over $60 \%{ }^{15}$. They are a significant contributor to the morbidity and mortality of these children. Early recognition and treatment of CHDs increases life expectancy and quality of life in children with $\mathrm{DS}^{16}$. Atrio-ventricular septal defect (AVSD), ventricular septal defect (VSD), atrial septal defect (ASD) and patent ductus arteriosus (PDA) are the most common forms of CHDs. Recent reports have shown that the distribution of CHDs in children with DS may have ethnic and geographic variations. In epidemiological studies carried out in the United States and Europe, a complete form of AVSD reached the highest rate, affecting up to $60 \%$ of patients. Alternately, in Asia, isolated ventricular septal defects have been reported to be the most common defects, 
observed in about $40 \%$ of patients. In Latin America, a secundum type of atrial septal defect (ASD) was reported to be the most common lesion (40\%) ${ }^{17}$.

We conducted this descriptive study at independent university hospital Faisal Abad Pakistan to evaluate the various types of congenital heart defects and their frequency in children with Down's syndrome.

\section{METHODS}

This descriptive, cross-sectional hospital-based study was conducted in the Department of Pediatrics, Independent University Hospital Faisal Abad Pakistan. The objective of our study was to evaluate the various types of congenital heart defects and to determine their frequency in children with Down's syndrome presenting at Independent University Hospital. Duration of study was 3 years from January 2010 to December 2012.

During this time period, 93 children between the ages of day 1 to 12 years, diagnosed as Down's syndrome were included in the study. Selection of sample size was based on the availability of as much cases, convenience of conducting the study and estimation of appropriate sample size. Children from both inpatient and outpatient department (previously diagnosed as DS or not) were included in the study. Diagnosis of Down's syndrome was primarily based on its characteristic phenotypic appearance (Genetic testing was advised in each case but was left to the affordability of parents/caregivers due to financial reasons). Phenotypic characteristics used to diagnose DS included characteristic mongoloid facies with depressed nasal bridge, protruding-scrotal tongue, low set ears, upward slanting eyes, medial epicanthic folds, brachycephaly, short neck, short and broad hands, simian crease, clinodactyly, hypotonia. Children with mental retardation and/or hypotonia with or without CHDs but not having characteristic phenotypic features of Down's syndrome were excluded from the study.
Protocol of study was fully explained to the parents and/or caregivers of children included in the study in simple and plain language. Informed consent was taken from parents and/or caregivers in each case and confidentiality was assured. Clearance from the institutional ethical committee was obtained.

A detailed history, physical examination and evaluation of cardiovascular status (including Chest x-ray, Electrocardiogram and Echocardiography) were performed in each DS case and findings were recorded in a structured, preformed Performa. Variables of interest included age, sex, maternal age at birth and type and frequency of congenital heart disease.

The data was analyzed using IBM SPSS V-19 computer software and was presented through frequency tables and diagrams.

\section{RESULTS}

93 children, diagnosed as Down's syndrome on the basis of characteristic phenotype were analyzed for age, sex, maternal age, presence of CHDs and their type and frequency. The results of these variables of interest are summarized in tables I, II and figure 1.

\begin{tabular}{|c|c|c|}
\hline \multirow{4}{*}{$\begin{array}{c}\text { Age } \\
\text { Mean age } \\
(7 \pm 4 \text { months })\end{array}$} & Age group & No. (\%) \\
\hline & $0-12$ months & $68(73.2 \%)$ \\
\hline & $1-6$ years & $20(21.5 \%)$ \\
\hline & $7-12$ years & $5(5.3 \%)$ \\
\hline \multirow{2}{*}{$\begin{array}{c}\text { Sex } \\
\text { Male : Female } \\
2.5: 1\end{array}$} & Male & Female \\
\hline & 67 (72\%) & $26(28 \%)$ \\
\hline \multirow{2}{*}{$\begin{array}{l}\text { Maternal age at birth } \\
\text { (Mean } 27 \pm 2 \text { years) }\end{array}$} & $<35$ years & $\geq 35$ years \\
\hline & $82(88 \%)$ & $11(12 \%)$ \\
\hline
\end{tabular}




\begin{tabular}{|l|c|c|}
\hline \multicolumn{1}{|c|}{ Type of CHD } & No. & \%age \\
\hline Ventricular septal defect (VSD) & 29 & 60.4 \\
\hline Atrioventricular septal defect (AVSD) & 14 & 29.1 \\
\hline Atrial septal defect (ASD) & 02 & 4.1 \\
\hline Patent ductus arteriosis (PDA) & 02 & 4.1 \\
\hline Tetrology of Fallots (TOF) & 01 & 2.0 \\
\hline
\end{tabular}

Table-II. Types of CHDs and their frequency in DS children with CHDs $(n=48)$

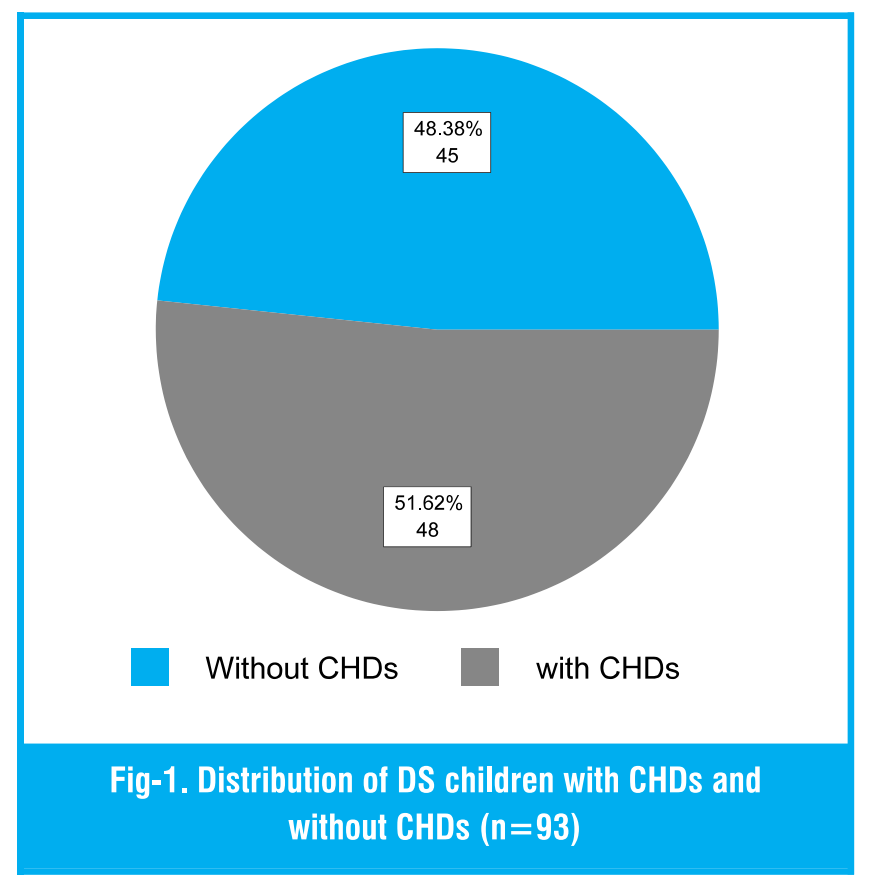

$68(73.2 \%)$ children with DS presented during the first year of life. This was due to developmental delay, floppiness or symptoms of associated CHDs recognized by their parents/caregivers or attending physician when compared with other age-matched children. Similarly, a significant number of DS children, $20(21.5 \%)$ presented after 1st year of life due to similar reasons especially during the second year of life. Mean age was $7 \pm 4$ months. DS children with CHDs $(n=48)$ when analysed for age distribution, following results were found. 36 (75\%) children belonged to 0 to 12 months age group, 11(22.9\%) children belonged to 1 to 6 years age group and only 1 $(2.1 \%)$ child belonged to 7 to 12 years age group. This was due to early presentation of most commonly associated CHDs with DS.

Male predominance with male to female ratio of 2.5: 1 was noted among 93 DS children. DS children with CHDs $(n=48)$ also showed a similar pattern with 32 children being males and 18 children being females (male: female, 1.7:1). Maternal age (Mean 27 \pm 2 years) was higher considering the trend of early marriages in our society.

In DS children with CHDs ( $n=48)$, VSD $(29,60.4 \%)$ and $\operatorname{AVSD}(14,29.1 \%)$ were major types of congenital heart defects, accounting for almost $90 \%$ of children with DS and CHDs.

\section{DISCUSSION}

Frequent (from 20 to over 60\%) association of congenital heart defects (CHDs) with Down's syndrome (DS) and their early presentation, makes them a significant contributor to the morbidity and mortality of these children. Review of current literature also shows ethnic and geographic variations in types and frequency of CHDs in children with $\mathrm{DS}^{15-17}$.

The results of our study are comparable with a similar study conducted by Khan I, Muhammad $\mathrm{T}^{18}$ at Department of Pediatrics, Postgraduate Medical Institute, Lady Reading Hospital, Peshawar, Pakistan. Their study also showed a higher incidence of CHDs $(31,56.36 \%)$ in DS children $(n=55)$ with VSD being most common $\mathrm{CHD}(7,22.6 \%)$. Male predominance was also present in DS children included in their study with or without CHDs (male to female ratio of 1.5:1 and 1.7:1 respectively).Unlike our study, they also reported other types of CHDs in DS children including Multiple cardiac lesions (ASD+PDA, VSD+PDA), Pentology of Fallots and Partial anomalous pulmonary venous drainage. Like our study, they also diagnosed DS based on its typical phenotypic characteristics. 
A study conducted in Kashmir, India by Ashraf et al ${ }^{19}$ also found VSD (48\%) the major type of CHD in DS children. Similar results of VSD predominance in DS children were reported by studies conducted in China (43.6\%) and Saudi Arabia (33.3\%) $)^{20,21}$.

Atrioventricular septal defect (AVSD) was observed in 14 (29.1\%) DS children in our study. This is lower than reported by researchers from other regions like Ali et $\mathrm{al}^{22}(48 \%)$ in Sudanese children with DS and by Freeman et $\mathrm{al}^{23}(45 \%)$ in American children with DS. But study conducted by Khan I, Muhammad $\mathrm{T}^{18}$ in Pakistan found AVSD in 19.4\% DS children which is comparable to our study. This obvious difference may be due to genetic variations related to ethnicity and geographic location of study population ${ }^{17}$.

Isolated PDA (4.1\%) and isolated ASD (4.1\%) were found in 4 patients (2 cases each) in our study. The study conducted by Khan I, Muhammad $\mathrm{T}^{18}$ showed a higher incidence (PDA, 19.4\% and ASD, 16.1\%). The studies conducted in Europe (5\%), Sudan (5\%) and USA (8\%) show a lower incidence of these lesions which is similar to our study ${ }^{24}$.

CHDs found in DS children are primarily acyanotic but our study found 1 case (2.0\%) with Tetralogy of Fallots (TOF). TOF has been reported as the most common cyanotic CHD in children with DS. Studies conducted by Khan I, Muhammad $\mathrm{T}^{18}(6.4 \%)$, Freeman et $\mathrm{al}^{23}$ (4\%), Abbag Fl. ${ }^{21}(5.3 \%)$, Lo NS et al ${ }^{20}$ (6\%) and AkbariAsbagh P. $^{25}(6.2 \%)$ also reported TOF in children with DS.

Limitations of our study include:

1. Lack of genetic testing in all subjects for diagnosis of DS and resultant lack of analysis of CHDs based on results of genetic analysis.

2. Our study was hospital-based not populationbased.

\section{CONCLUSIONS}

Congenital heart disease (CHD) is frequently associated with Down's syndrome (DS). Ventricular septal defects and atrioventricular septal defects are the most common forms of CHDs in DS children of our region. Their earlier presentation (in infancy) and significant contribution to the morbidity and mortality of DS children warrants early diagnosis of DS and mandatory screening of all DS children for associated CHDs.

Copyright(C) 20 Sep, 2013.

\section{REFERENCES}

1. Roizen NJ, Patterson D. Down's syndrome. Lancet. 2003 Apr 12; 361(9365):1281-9.

2. Summar K, Lee B. Down Syndrome and Other Abnormalities of Chromosome Number. In: Kliegman RM, Stanton BF, Schor NF, Behrman RE. Nelson Textbook of Pediatrics, 19th ed. Philadelphia: WB Saunders; 2011. p. 399-404.

3. Patton MA. Genetics. In: Mcintosh N, Helms P, Smyth R, editors. Forfar and Arneil's textbook of pediatrics. 6th ed. Spain: Churchill Livingstone 2004. p. 407-40.

4. Shin M, Besser LM, Kucik JE, et al. Prevalence of Down syndrome among children and adolescents in $\mathbf{1 0}$ regions of the United States. Pediatrics. 2009; 124(6):1565-1571.

5. Reeves RH, Baxter LL, Richtsmeier JT. Too much of a good thing: mechanisms of gene action in Down syndrome. Trends Genet. Feb 2001; 17(2):83-8.

6. Antonarakis SE, Lyle R, Dermitzakis ET, Reymond A, Deutsch S. Chromosome 21 and down syndrome: from genomics to pathophysiology. Nat Rev Genet. 2004 0ct; 5(10):725- 38.

7. Kagan KO, Wright D, Baker A, Sahota D, Nicolaides KH. Screening for trisomy 21 by maternal age, fetal nuchal translucency thickness, free beta-human chorionic gonadotropin and pregnancy-associated plasma protein-A. Ultrasound Obstet Gynecol. Jun 2008; 31(6):618-24.

8. Baum RA, Nash PL, Foster JE, Spader M, Ratliff-Schaub 
K, Coury DL. Primary care of children and adolescents with Down syndrome: an update. Curr Probl Pediatr Adolesc Health Care. Sep 2008; 38(8):241-61.

9. Shapiro BL. Down syndrome and associated congenital malformations. J Neural Transm Suppl. 2003; (67):207-14

10. Lubec G, Engidawork E. The brain in Down syndrome (TRISOMY 21). J Neurol. 2002 0ct; 249(10):1347-56.

11. Vis JC, Duffels MG, Winter MM, Weijerman ME, Cobben JM, Huisman SA. Down syndrome: a cardiovascular perspective. J Intellect Disabil Res. May 2009; 53(5):419-25.

12. Rabin KR, Whitlock JA. Malignancy in children with trisomy 21. Oncologist. Feb 2009; 14(2):164-73.

13. Nieuwenhuis-Mark RE. Diagnosing Alzheimer's dementia in Down syndrome: Problems and possible solutions. Res Dev Disabil. 2009; 30(5):827-838.

14. Popova G, Paterson WF, Brown A, Donaldson MD. Hashimoto's thyroiditis in Down's syndrome: clinical presentation and evolution. Horm Res. 2008; 70(5):278-84

15. Nisli K. Prevalence of congenital heart defects in patients with Down's syndrome. J Pediatr (Rio J). 2009; 85(5):377-378.

16. Weijerman ME, van Furth AM, Vonk Noordegraaf $A$ et al. Prevalence, neonatal characteristics and first-year mortality of Down syndrome: a national study. J Pediatr. 2008; 152:15-19.

17. Freeman SB, Bean LH, Allen EG et al. Ethnicity, sex, and the incidence of congenital heart defects: a report from the National Down Syndrome Project. Genet Med. 2008; 10:173-180.

18. Khan I, Muhammad T. Frequency and pattern of congenital heart defects in children with Down's syndrome. Gomal J Med Sci 2012; 10: 241-3.

19. Ashraf M, Malla RA, Chowdhry J, Malla Ml, Akhter M, Rahman $A$, et al. Consanguinity and pattern of congenital heart defects in Down's syndrome in Kashmir, India. Am J Sci Ind Res 2010: 1: 573-7.

20. Lo NS, Leung PM, Lau KC, Yeung CY. Congenital cardiovascular malformations in Chinese children with Down's syndrome. Chin Med J Eng 1989; 102 : 382-6.

21. Abbag Fl. Congenital heart diseases and other major anomalies in patients with Down's syndrome. Saudi Med J 2006; 27:219-22.

22. Ali SK. Cardiac abnormalities of Sudanese patients with Down's syndrome and their short-term outcome. Cardiovasc J Afr 2009; 20: 112-5.

23. Freeman SB, Taft LF, Dooley KJ, Allran K, Sherman SL, Hassold TJ, et al. Population-based study of congenital heart defects in Down syndrome. Am J Med Genet 1998; 80: 213-7.

24. Elmagrpy Z, Rayani A, Shah A, Habas E, Aburawi EH Down syndrome and congenital heart disease: why the regional difference as observed in the Libyan experience? Cardiovasc J Afr 2009; 20: 112-5.

25. Akbari-Asbagh P, Ghasemi M, Zamani A. Prevalence of congenital heart defects in children with Down's syndrome in Imam Khomeini Hospital, Tehran. Iran J Pediatr 2007; 17: 95-100. 


\section{AUTHOR(S):}

1. DR. SHAKIL AHMAD

Associate Professor Paediatrics

MBBS, FCPS

Independent Medical College Faisal Abad

2. DR. IMRAN SARWAR

Assistant Professor Paediatrics

MBBS, FCPS

Independent Medical College Faisal Abad

3. DR. NISAR KHAN SAJID

Assistant Professor Paediatrics

MBBS, FCPS

Independent Medical College Faisal Abad

\section{Correspondence Address: \\ Dr. Shakil Ahmad \\ Associate Professor Paediatrics \\ MBBS, FCPS \\ Independent Medical College Faisal Abad}

Article received on: 26/08/2013 Accepted for Publication: $\quad 20 / 09 / 2013$ Received after proof reading: 03/12/2013

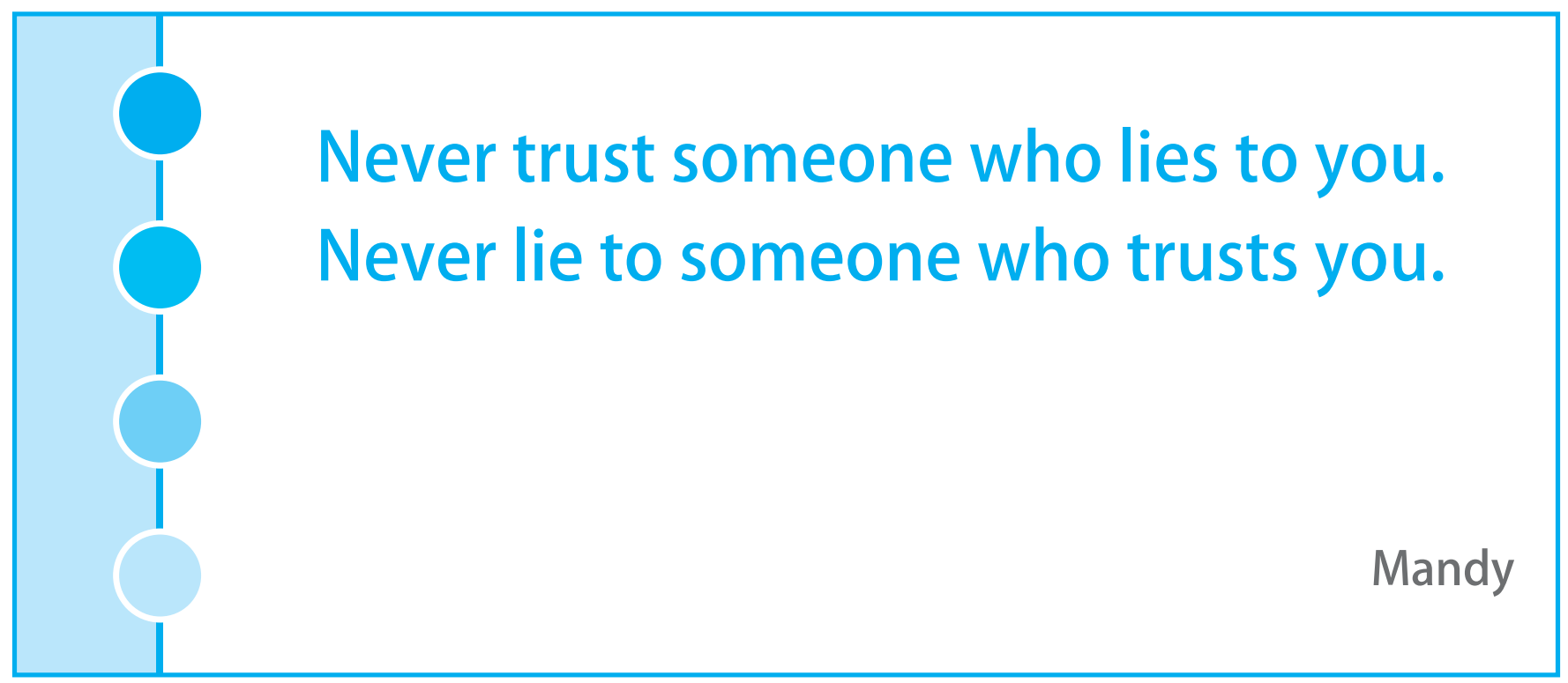

